\title{
Banka Tercihini Belirleyen Kriterlerin ENTROPİ Yöntemi İle Ağırlıklandırılması: Giresun İli Örneği (Weighting the Criteria that Determine the Bank Preference with the ENTROPY Method: The Case of Giresun Province)
}

\author{
Alper KARAVARDAR iD a Arif ÇİLEK iD b \\ a Giresun Üniversitesi, İktisadi ve İdari Bilimler Fakültesi, İşletme Bölümü, Giresun, Türkiye. akaravardar@yahoo.com \\ b Giresun Üniversitesi, Bulancak Kadir Karabaş U.B.Y.O., Uluslararası Ticaret ve Finansman Bölümü, Giresun, Türkiye. \\ arifcilek86@gmail.com
}

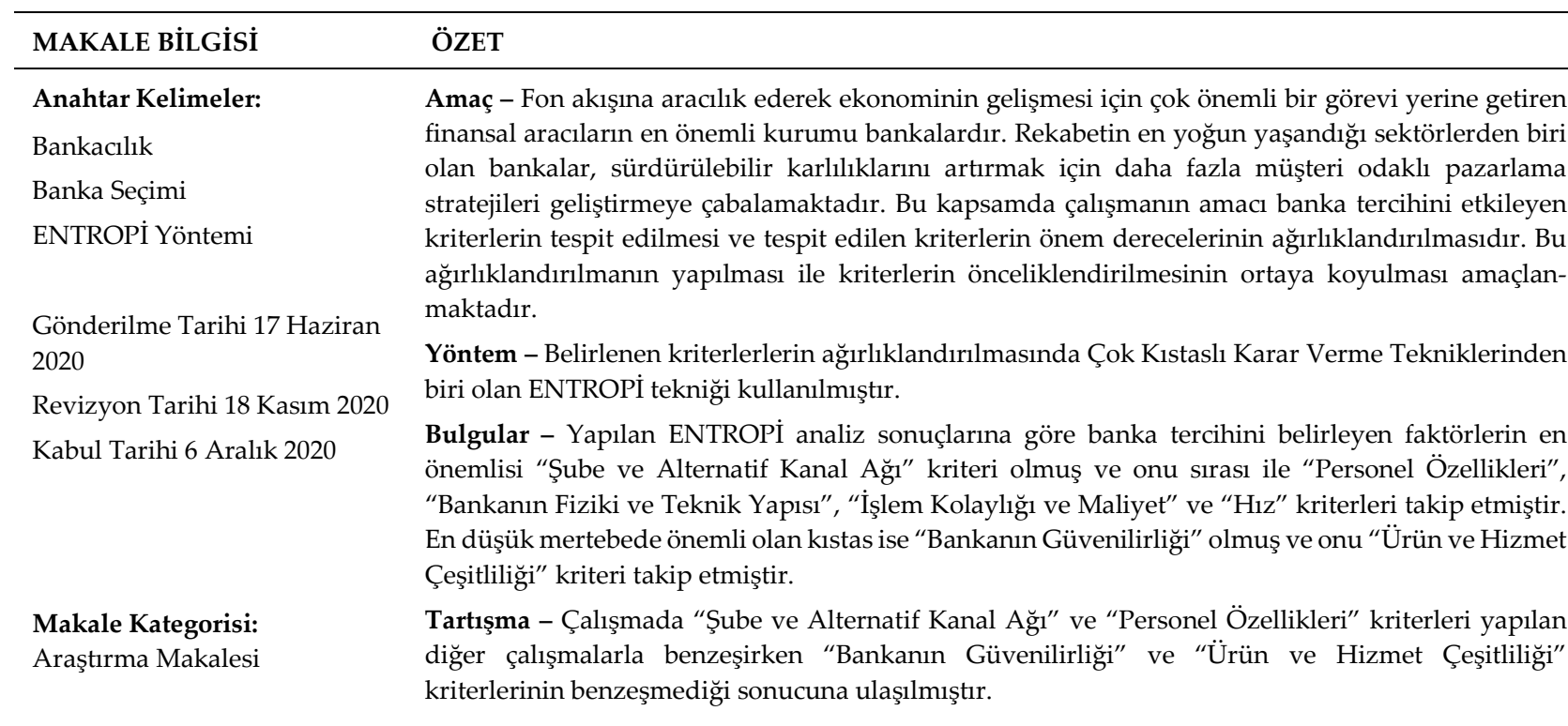

\begin{tabular}{ll}
\hline ARTICLE INFO & ABSTRACT \\
\hline Keywords: & $\begin{array}{l}\text { Purpose - Banks are the most important institutions of financial intermediaries that fulfill a very } \\
\text { important task for the development of the economy by mediating the flow of funds. The banking } \\
\text { Banking } \\
\text { sector,which is one of the sectors with the most intense competition, strives to develop more } \\
\text { customer oriented marketing strategies to increase their sustainable profitability. In this context, the } \\
\text { aim of the study is to determine the criteria that affecting the bank preference and to weight the } \\
\text { importance of the determined criteria. It is aimed to reveal the priority of the criteria by making this } \\
\text { weighting. }\end{array}$ \\
$\begin{array}{l}\text { Design/methodology/approach - ENTROPY technique, which is one of the Multi-Criteria Decision } \\
\text { Received 17 June 2020 }\end{array}$ & $\begin{array}{l}\text { Making Techniques, has been used in weighting the determined criteria. } \\
\text { Revised 18 November 2020 } \\
\text { Accepted 6 December 2020 } \\
\text { determines the bank preference has been the "Branch and Alternative Channel Network" criteria, } \\
\text { followed by the "Personnel Features", "Physical and Technical Structure of the Bank", "Ease of } \\
\text { Operation and Cost" and "Speed" criteria. The least important criterion was "Reliability of the Bank" } \\
\text { followed by the "Product and Service Diversity" criterion. } \\
\text { Discussion - In the study, while the criteria of "Branch and Alternative Channel Network" and } \\
\text { Research Article }\end{array}$ \\
$\begin{array}{l}\text { "Personnel Features" were similar to other studies, it was concluded that the criteria of "Reliability } \\
\text { of the Bank" and "Product and Service Diversity" were not similar. }\end{array}$
\end{tabular}




\section{GİRIŞ}

Bankalar finansal sistemin en önemli kurumlarından biridir. Fon fazlası olan ekonomik birimlerden topladıkları fonları fon noksanı olan ekonomik birimlere aktararak bir köprü görevi üstlenmektedir. Başka bir deyişle bankacılık sisteminin aracılık işlevinin gelişmesi ekonomik canlılığın devam ettirilmesine, bu işlevlerin hızlanmasına ve ekonomik büyümeye katkı sağlamaktadır (Akın, 2019:72).

Günümüzde küreselleşmenin yol açtığı sonuçlar, tüketicilerin davranış kalıpları ve tercihlerindeki değişmeler ve gelişmeler, yoğunlaşan rekabet ortamı ve çok kısa zaman zarfı içerisinde değişen bankacılık mevzuatları, sektörü oldukça stres altına almaktadır (Çolak, 2003:22). 1980'lerin son yıllarından itibaren bankacılık sektörü liberalleşmiş ve rekabet hız kazanmıştır (Adamu ve Adeola, 2012:82). Özellikle telekominikasyon ve bilgi teknolojisi alanındaki gelişmeler bankacılık sektöründe bir devrim yaratmaktadır. Bu teknolojinin gelişmesi ile elektronik ticaretin yeni bir devrim vadettiği görülmektedir (Sohail ve Shanmugham, 2003:208). Bu bağlamda iletişim teknolojilerindeki ve bilgi teknolojilerindeki değişimler ve gelişmeler artan yoğun rekabetle beraber bankacılık sektörünün pazarlama stratejilerini geliştirmede izledikleri yöntemleri farklılaştırmaktadır (Usta, 2005:279).

Banka seçimi yaparken birçok farklı kriteri finansal tüketiciler göz önünde bulundurmaktadır. Bankanın pazarlama stratejilerinin planlanmasında bu kriterler belirleyici olmaktadır. Banka tercihini belirleyen kriterlere ilişkin Türkiye'de yapılan çalışmaların bazıları özetlenmeye çalışılııştır. ATM'lerin yaygın bir lokasyon ağında olması (Karamustafa ve Yıldırım, 2007:56), banka personeline olan itimat, personelin bilgi seviyesi, ayrıca banka personelinin kibar ve güler yüzlü olması, bankanın sunmuş olduğu hizmetlere erişilebilirlik (Taşkın vd., 2010:18-19), problemlerin hızlı bir şekilde çözülmesi, ürün ve hizmet çeşitliliği, işlem kolaylığı ve maliyeti, bankada çok sayıda insan kalabalığının olmaması, bankanın teknik ve fiziki yapısı (Cebeci ve Çabuk, 2016:65) banka tercihinde etkili olmuştur.

Son yıllarda konuya ilişkin gelişmekte olan ülkelerde de çalışmalar yapılmıştır. Bu bağlamda yapılan çalışmaların birkaçınının özetlenmesi uygun olacaktır. Etkin ve hızlı hizmet verilmesi, telefon ve internet bankacılığı hizmetlerinin sunulması, çok sayıda noktada ATM'nin bulunması (Okpara ve Onuoha, 2013:12), banka personelinin kibar ve samimi olması, ATM hizmetleri, işlem hızı, hizmet sunumu, bankanın fiziki görünüşü, bankanın konumu, şube sayısı, bankaya olan güven duygusu (Tehulu ve Wondmagegn, 2014:57), hizmet kalitesi, bankanın imajı, personelin tutumu ve önerileri, iletişim ve müşteri hizmetleri (Ibrahim vd., 2020:16) banka tercihinde etkili kriterler olarak tespit edilmiştir.

Banka tercihi kriterleri konusunda gelişmiş ülkelerde yapılan çalışmalar incelendiğinde ise, Kanada'da yapılan çalışmada banka personelinin içtenliğinin en önemli seçim kriteri olduğunu, sırasıyla bu kriteri işlem süreleri, sırada bekleme süreleri, bankanın bulunduğu lokasyon ve personelin bilgi seviyesi kriteri olduğu (Laroche vd., 1986:51), Finlandiya'da yapılan çalışmada en önemli kriterlerin sırasıyla bankadaki karşılanma, hızlı ve etkin hizmet verilmesi, düşük ücret ve komisyonlar, personelin içtenliği ve güven algısı (Holstius ve Kaynak, 1995:14) olduğu tespit edilmiştir.

Günümüzde müşteriler almış oldukları ürün ve hizmetlerde artan seçim kriterleri ile karşı karşıya olup, kalite, hizmet ve değer yargılarına göre tercihlerini yapmaktadırlar (Naktiyok ve Küçük, 2003:227). Bir bankanın ürün ve hizmetlerini geliştirerek doğru kanallardan doğru ürünleri doğru müşterilere sunması o bankanın tercih edilmesine etken olabilir.

Bu çerçeve de çalışmanın amacı, Giresun Il'indeki banka tercihi kriterlerinin tespit edilmesi ve tespit edilen kriterlerin ENTROPI tekniği ile ağırlıklandırılması ve sonuçların yorumlanmasıdır. Çalışmanın sonraki aşamalarında sırasıyla banka tercihine ilişkin ulusal ve uluslararası alan yazın üzerine değinilmiştir. Çalışmanın tekniğini meydana getiren ENTROPİ izahları yapılmıştır. ENTROPİ tekniğinin Giresun İli banka seçimi için uygulaması ortaya koyulmuştur. Çalışmanın son kısmında ise tartışma, sonuç ve daha sonra yapılacak çalışmalarla ilgili görüşler ileri sürülmüştür.

\section{LITTERATÜR}

Banka müşterilerinin banka tercihinde hangi kriterleri temel aldıkları araştırmacılar açısından çok fazla dikkat çeken bir konu olmuştur (Rao ve Sharma, 2010:56). Bankacılık alanına yönelik ENTROPİ yönteminin 
kullanıldığı az sayıda çalışmaya rastlanılmıştır. Bu kapsamda banka seçimini belirleyen kriterler konusunda yapılan çalışmalardan bazıları aşağıda verilmiştir.

Holstius ve Kaynak (1995), Finlandiya'da müşterilerin banka seçimi yaparken tercih ettikleri kriterleri araştırmış, çalışmanın sonucunda 258 müşterinin banka seçimi yaparken "bankadaki karşılamaya", "hızlı ve etkin hizmet alınmasına", "ücret ve komisyonların düşük olmasına", "personelin içten olmasına" ve "bankanın güvenliğine" önem verdiklerini ortaya koymuştur.

Delvin ve Gerrard (2005), banka seçim kriterlerinde çoklu bankacılığı analiz etmiş, "kredi faizlerinin düşük olmasının" ve "kaliteli hizmet sunumunun" banka seçiminde önemli kriterler olduğu sonucuna ulaşmıştır. Ayrıca ana bankanın haricinde ikinci banka seçiminde "başkalarının önerisinin" çok daha etkili olduğunu ortaya koymuştur.

Karamustafa ve Yıldırım (2007) tarafından Kayseri ilinde tüketicilerin banka seçiminin araştırıldığg çalışmanın sonucunda, bireysel müşterilerin banka seçiminde en fazla önem verdiği kriterlerin "hukuki açıdan güvenilirlik", "bekleme süresinin kısalığı ve hızl hizmet", "ATM sayısının ve ATM'den yapılacak finansal işlem sayısının fazlalı̆̆ı" olduğu belirtilmektedir.

Mokhlis vd. (2009), Malezya'da genç yetişkinler üzerinde yaptığı çalışmada tek banka kullanıcılarının ve çok sayıda banka kullanıcılarının banka seçim kriterlerini araştırmış, hem tek hem de çoklu banka kullanıcılarının banka seçim kriterlerinin "bankanın çekiciliği", "şube ve ATM hizmeti", "finansal faydalar" ve "güvenlik hissi" olduğu sonucuna varmışlardır.

Taşkın vd. (2010), Bursa'daki banka işletmeleri için tüketicilerin banka tercihlerini etkileyen faktörlerin belirlenmesi ve banka pazarlama stratejilerini oluşturmada yardımcı olacak bilgileri araştırmış, çalışmanın sonucunda "güvenilir olma", tutundurma stratejileri açısından "bankanın reklamı", "sosyal ve teknik yeterlilik", "fiziksel görünüm", "ulaşılabilirlik" kriterlerinin banka seçiminde etkili olduğu sonucuna varmışlardır.

Aregbeyen (2011), Nijerya'da ticari müşteriler tarafından banka seçim kriterlerini araştırmış, "fonların güvenliğinin" ve "teknoloji tabanlı hizmetlerin kullanılabilirliğinin" müşterilerin banka seçiminde önemli etkenler olduğunu ortaya koymuştur.

Chigamba ve Fatoki (2011), banka seçiminin belirleyicilerini kolay örnekleme yöntemi ile anket uygulayarak Güney Afrika'da üniversite öğrencileri üzerinden araştırmış, "hizmet", "yakınlık", "çekicilik"," öneriler", "pazarlama" ve "fiyat" faktörlerini banka seçiminin belirleyicileri olarak tespit etmiştir.

Narteh vd. (2011), Ganalı öğrencilerin banka seçimi konusunda daha derin bir bakış açısı sunmayı amaçladı̆̆ı çalışmada, katılımcılara anket uygulanmış ve faktör analizi yöntemi kullanılmıştır. "Personelin imajı, tutumu ve davranışı", "teknolojiye açılım" ve "hesapların korunmasının" öğrenci olan müşterilerin banka tercihini etkileyen temel faktörler olduğu belirlenmiştir.

Adamu ve Adeola (2012) Nijerya'da yaptıkları çalışmada bireylerin belirli bir bankada hesap açma kararını etkileyen faktörleri araştırmış, "mevduatın güvenliğinin" en çok dikkate alınan faktör olduğu, bunu "müşteri ilişkilerinin izlediğini" ve en az dikkate alınanın ise "faiz oranları" faktörü olduğu sonucuna ulaşmıştır.

Hasan vd. (2012), Pakistan'da yaptığı çalışmada İslami banka seçim kriterlerini araştırmış, "yüksek karlılı" ve "düşük hizmet maliyetlerinin" en önemli tercih sebebi olduğu sonucuna ulaşmıştır. Ayrıca İslami bankacılığın tüketiciler tarafından seçilmesinde "dini güdülerinde" etkili olduğu belirtilmiştir.

Junior vd. (2013), müşterilerin Gana'daki bireysel bankacıllk tercihini belirlemek için Berekum'da seçilen 5 bankanın müşterisinden veri elde etmek için anket uygulanmış, anket sonucunda "mevduat güvenliğinin" ve "müşterilerin bankalara kolay ulaşım sağlamasının" banka tercihinde önemli faktörler olduğu belirlenmiştir.

Okpara ve Onuoha (2013), Nijerya'da 250 üniversite öğrencisine ticari banka seçiminin belirlemek için anket uygulamış, frekans analizi ve faktör analizi yöntemlerini kullanmış, çalışmanın sonucunda banka tercihini etkileyen faktörlerin en önemlisinin "etkili, hızl ve düşük maliyetle hizmet" verilmesi olduğunu tespit etmiştir.

Özsoy vd. (2013), Bolu İl'inde katılım bankalarının tercih edilme sebeplerini araştırmış, üç ayrı katılım bankası müşterilerine 217 anket verileri ile faktör analizi uygulanmıştır. Çalışmanın sonucunda katılım bankacılığının tercih edilmesinin en önemli kriterlerinin sırasıly "hizmet/ürün kalitesi", "imaj ve güven", "personel kalitesi" ve "dini/çevresel motivasyon" kriterleri olduğu ortaya konulmuştur. 
Tehulu ve Wondmagegn (2014), Etiyopya'da banka seçim kararını belirlemek için 5 ticari banka müşterisine 204 anket uygulanmış, çoklu regresyon modeli sonuçlarına göre banka seçiminde "personelin nazik ve güler yüzlü olması", "ATM hizmetleri", "hizmet kalitesi", "bankanın fiziksel görünümü" ve "güvenlik hissinin" önemli faktörler olduğu sonucuna ulaşmıştır.

Yıldız vd. (2014), islami bankalara yönelik tüketici tutumlarını ve tüketicilerin banka seçimini etkileyen kriterleri araştırdığı çalışmada "işlemlerde şeffaflık", "islam hukuku ve ilkeleri", "çalışanların etik davranışı", "düşük hizmet ücretleri", "hızl ve etkin işlem", "24 saat ATM hizmetleri", "ATM konumlarının erişilebilirliği", "faizsiz kredilerin să̆lanması", "banka itibarı", "hesap açılış kolaylı̆̆ı", "yıllık aidat ödemesiz banka kartı", "güzel banka atmosferi", "hızl ve etkin gişe hizmeti", "deneyimli yönetim ekibi", "banka personelinin samimiyeti", banka yerinin erişilebilirliği", "şube sayısı", "fon elde etme kolaylı̆̆ı", "İslami ürün ve hizmetlerin sağlanması", "yatırım ürünlerinde kar paylaşımı", "internet bankacılığı", "akrabaların tavsiyesi", "Cuma bankacilığı" ve "arkadaş tavsiyesi" kriterlerini dikkate almış, analizler sonucunda "İslam hukuku ve ilkelerinin" tüketicilerin İslami bankaları tercih etmesinde en etkili kriter olduğunu ortaya koymuştur.

Cebeci ve Çabuk (2016) Giresun'da tüketicilerin banka tercihini etkileyen faktörlerin belirlenmesine yönelik yaptığ 1 çalışmada faktör analizi sonucu 7 faktör tespit etmiştir. "Şube ve alternatif kanal ă̆ğ", "personel özellikleri", "işlem kolaylığı ve maliyet", "bankanın fiziksel ve teknik yapısı", "ürün ve hizmet çeşitliliği", "bankanın güvenilirliği", ve "hız" kriterlerini banka tercihinde etkili olan kriterler olarak belirlemiştir.

Çöllü ve Sevim (2017), yaptığı çalışmada Türkiye' de banka seçimini belirleyen faktörleri Giresun şehri örneği üzerinden analiz etmiştir. Çalışmada frekans analizi ve faktör analizi yöntemleri uygulanmıştır. Frekans analizine göre "bekleme sürelerinin kısalı̆̆ı" müşterilerin en önem verdiği faktördür. Faktör analizine göre ise müşteriler banka seçiminde "fiziksel olanaklara" daha fazla önem vermektedirler.

Tepeli ve Daşkıran (2019), Muğla Sıtkı Koçman Üniversitesi'nde mali tüketicilerin banka seçimini tespit etmek amacıyla yaptıkları çalışmada İktisadi ve İdari Bilimler Fakültesi'nde görevli 22 akademik personele anket uygulanmış ve Konjont Analizi kullanılmıştır. Analiz sonucunda mali tüketicilerin banka seçiminde en fazla önemli olan etmen "bankacılık işlemleri", "şube ve alternatif kanal ă̆ı" ve "personel özellikleri" olarak belirlenmiştir.

Ibrahım vd. (2020), Gana' da üniversite birinci sınıf öğrencilerinin banka tercihini belirlemek amaciyla yaptığı çalışmada 320 anket uygulanmış, çalışma sonucunda sırasıyla "hizmet kalitesi", "bankanın imajı", "personelin tutumu ve önerileri", "iletişim ve müşteri hizmetlerinin" Gana'daki banka seçim kararını etkileyen faktörler olduğu tespit edilmiştir.

Yapılan alan yazın taramasında banka tercihini belirleyen kriterlerin önceliklendirilmesinin ortaya konulması amacıyla az sayıda çalışmaya rastlanılmış olması çalışmayı önemli kılmaktadır. Ayrıca kullanılan yöntem ve çalışmanın konu alındığı İl itibari ile başka bir çalışmanın olmaması da çalışmayı diğer çalışmalardan farklı kılmakta ve alan yazına katkı sağlayacağı düşünülmektedir.

\section{YÖNTEM}

Çalışmanın etik açıdan uygunluğu için T.C. Giresun Üniversitesi Rektörlüğü Sosyal Bilimler Fen ve Mühendislik Bilimleri Araştırmaları Etik Kurulu Başkanlığı'na başvurulmuştur. Kurulun 4 Kasım 2020 tarih ve 04/3 sayılı Etik Kurulu kararına göre etik açıdan bir sakınca görülmemiş olup, uygun bulunmuştur.

Çok Kriterli Karar Verme Yöntemleri (ÇKKV), sonuca ulaşmak için belirlenen hedefi çok fazla parametre aracılığıyla uygulayan tekniklerdendir. Karar verme problemlerine çözüm olabilecek bir grup vasıtalara ihtiyaç duyulmasıyla beraber geliştirilmeye $1960^{\prime} 1$ y yıllarda başlanmıştır. Karar verme sistemini denetim altında tutan ve karar neticesini olabildiğince basit ve hızlı elde etmede kullanılan, seçenekler içerisinde karar verme probleminin çok sayıda olduğu durumlarda günümüzde çok sayıda alanda faydalanılan teknikler içerisindedir (Herişçakar, 1999: 245-2). Diğer taraftan çalışmanın doğrulanabilirliğini, onaylanabilirliğini ve güvenilirliğini ortaya çıkaran etmen ÇKKV tekniklerinden Entropi'nin uygulama adımlarıdır. Entropi yöntemi, ortaya konulan bir probleme yönelik minimum belirliliği ya da maksimum belirsizliği açıklamada kullanılan etkin aynı zamanda gerçeği yansıtan önceliklendirme yöntemlerinden biridir. İlaveten yöntem, insan kaynaklı hataları da ortadan kaldırmakta ve düzensizlik derecesi yöntem küçüldükçe azalmaktadır 
(Çiçek, 2013:59; Korucuk vd., 2020:162). Bu bağlamda çeşitli alanlarda ENTROPİ yönteminin kullanıldığı bazı çalı̧̧malar incelenebilir. Örneğin;

Bankacılık sektörünün finansal performanslarını Çınar (2004) yılında, Lee, vd., (2012) taşımacılık şirketlerinin finansal durumlarını, Chen vd., (2014) çalışmasında gıda atık emniyetinin kıstaslarını, Alp vd., (2015) kurumsal sürdürülebilirlik performanslarını, Ömürbek vd., (2016) otomotiv şirketlerinin başarılarını, Korucuk vd., (2018) ülkelerin uluslararası ticaret performans kriterlerini, Korucuk vd., (2019) otel işletmelerinde hizmet kalitesi standartlarını, Memiş (2019) konaklama işletmelerinde yeşil yönetim uygulamalarını ENTROPİ yöntemi ile ağırlıklandırmışlardır. Başka bir bakış açısıyla ÇKKV teknikleri istatistiksel çözümlemelerde gerçekleştiği şekilde, bir ana kütleye ilişkin genelleme yapmak için örneklem kütlesine uygulanan tekniklerden biri değildir. Bu teknikler öznel ve nesnel kıstasların tek bir çalışmada analiz edilebildiği ve uzman fikirleri doğrultusunda analizin yapıldığı tekniklerdendir. Bununla birlikte bu tekniklerde bir küme yargısı gereğince uygulama yapılabilir. Benzer şekilde tek bir uzman fikri ile de uygulama ortaya koyulabilir (Korucuk vd., 2019:703). Bu çalışmada ÇKKV tekniklerinden ENTROPİ kullanılmış ve 15 uzman fikrine yer verilerek çalışma şekillendirilmiştir. Konunun paydaşları olan, Giresun Üniversitesi'nde öğretim üyesi olan, bankacılık ve finans alanında çalışan akademisyenlere (3), Giresun İl Merkezi'ndeki bankalarda en az on yıl tecrübesi olan, yönetici, pazarlama yetkilisi ve operasyon yetkilisi pozisyonunda çalışan bankacılara (10), Ticaret ve Sanayi Odası yetkililerine (2) toplamda 15 anket sunulmuştur. Ankete katılan kişiler çalışmada karar verici olarak dikkate alınmıştır.

$\mathrm{Bu}$ sınırlar içerisinde Giresun'da banka işletmelerinde banka tercihi faktörlerindeki kıstasların tespit edilmesinde Çok Kıstaslı Karar Verme (ÇKKV) tekniği olan ENTROPI tekniğinden yararlanılmışır. Kıstas ağırlıkları ENTROPİ ile tespit edilmiştir.

\subsection{ENTROPİ Ağırlık Tekniği}

Termodinamikte düzensizlik ve dağınıklığın ölçütü olarak bilinen ENTROPİ kavramı 1865 yılında Clausius tarafından ifade edilmiştir (Zhang vd., 2011: 444). Belirsizliğin ölçülü olarak kesikli olasılık dağılımı ile açıklanan bu kavram farklı birşekilde Shannon (1948) tarafından enformasyon teorisi açısından tanımlanmıştır. Pratikte teknikteki değişken azaldıkça intizamsızlık seviyesi de azalmaktadır (Wu vd., 2011:5163-5165). Entropi Ağırlık tekniğinin pratikteki aşamaları ise aşağıda gösterilmiştir (Abdullah ve Otheman, 2013, s.26; Malekian ve Azarnivand, 2016:416-417).

\section{Adım: Ilk Karar Matrisinin Meydana Getirilmesi}

Eşitlik (1)' de aşağıda yer alan biçimce ilk karar matrisi $\mathrm{m}$ adet karar seçeneği ve $\mathrm{n}$ adet değerlendirme kıstasına sahip olan çok kıstaslı karar sorunu için meydana getirilir.

$$
X_{m x n}=\begin{array}{cccc}
x_{11} & x_{12} & \ldots & x_{1 j} \\
x_{21} & x_{22} & \ldots & x_{11} \\
\vdots & \vdots & \ldots & \vdots \\
x_{m 1} & x_{m 1} & \ldots & x_{m n}
\end{array}
$$

2.Adım: Bașlangıc Illk Karar Matrisinin Normalize Sekle Getirilmesi

Normalizasyon hesaplamaları yapılırken kıstasların yarar (2) veya maliyet (3) taraflı olması durumuna göre aşağıda yer alan formüller kullanılır:

$$
\begin{array}{ll}
P_{i j}=\frac{x_{i j}-x_{j}^{\min }}{x_{j}^{\max }-x_{j}^{\min }} & \mathrm{i}=1,2,3, \ldots, \mathrm{m} \text { ve } \mathrm{j}=1,2,3, \ldots, \mathrm{n} \\
P_{i j}=\frac{x_{j}^{\max }-x_{i j}}{x_{j}^{\max }-x_{j}^{\min }} & \mathrm{i}=1,2,3, \ldots, \mathrm{m} \text { ve } \mathrm{j}=1,2,3, \ldots, \mathrm{n}
\end{array}
$$

Başlangıç matrisi normalize edilir. Daha sonra $\mathrm{R}=\left[\mathrm{r}_{\mathrm{ij}}\right] \mathrm{m} \times \mathrm{n}$ matrisinde gösterilir ve eşitlik (4) ${ }^{\prime}$ ten yararlanılmaktadır.

$$
P_{i j}=\frac{r_{i j}}{\sum_{i=1}^{m} r_{i j}}
$$

\section{Adım: Entropi Değerinin Bulunmast}

ENTROPI değişkeni (Ej), aşağıda yer alan eşitlik (5) aracılığıyla bulunmaktadır: 
$E_{j}=-k \sum_{i=1}^{m} P_{i j} \ln \left(P_{i j}\right) \quad \mathrm{i}=1,2, \ldots, \mathrm{m}$ ve $\mathrm{j}=1,2, \ldots, \mathrm{n}$

Bu formülde yer alan k sayısı, $\mathrm{k}=(\ln (m))^{-1}$ formülü aracılığı ile bulunmaktadır.

\section{Adım: Farklilaşma Derecelerinin Bulunması}

ENTROPİ değişkeninin farklılaşma ölçüsü (dj), eşitlik (6) aracılığı ile bulunmaktadır.

$$
\mathrm{dj}=1----E j ; \forall j
$$

\section{Adım: ENTROPI Ağırliğının Bulunması}

Her bir kıstasın objektif ağırlığı (Wj), eşitlik (7)'ya göre ortaya konulmaktadır:

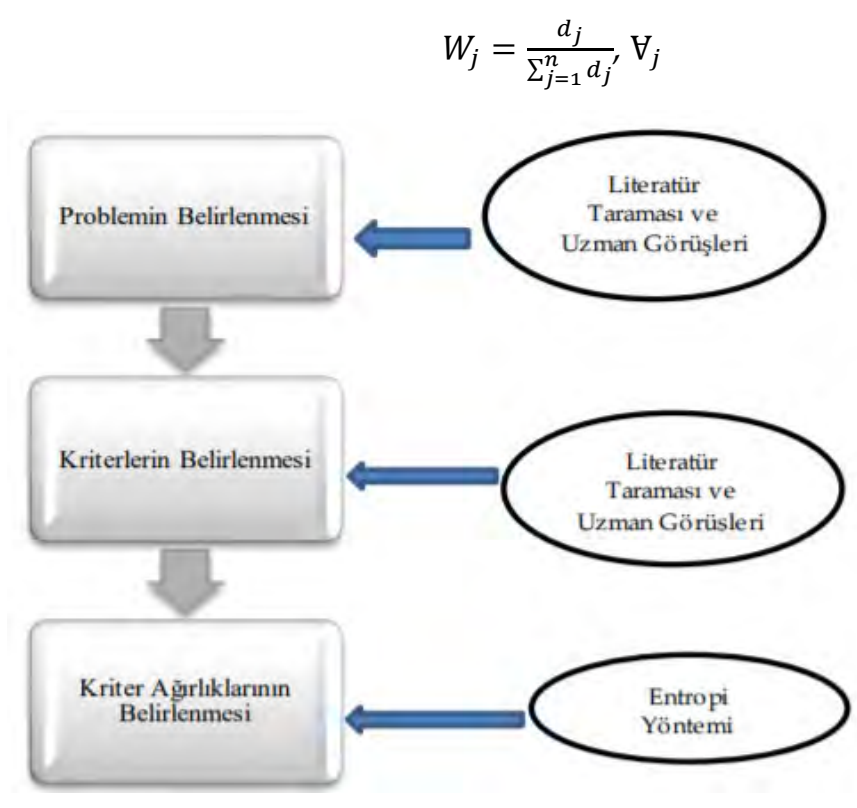

Şekil 1. ENTROPİ Uygulama Adımları

\section{BULGULAR}

Çalışmada, Giresun'da banka işletmelerinin tercihinde kullanılacak kriterlerin değerlendirilmesi için çok kıstaslı karar modeli oluşturulmuştur. Şekil 1'de gösterilen modelde ENTROPİ değerlendirme modeli aşamaları adım adım tatbik edilmiştir. Modele göre ilk olarak uzman görüşleri ile alan yazın taramasından yararlanılarak banka tercihlerine esas kıstaslar tespit edilmiştir. Avrupa'nın bazı gelişmiş ülkelerinde ve genel olarak ABD'de banka seçimi konusunda ilk çalışmaları yapan araştırmacılar (Anderson ve diğerleri, 1976; Tan ve Chua, 1986; Kaynak, 1986; Laroche ve diğerleri, 1986; Erol ve El Bdour, 1989; Holstius ve Kaynak, 1995) durumu açıklamış ve gelecek yıllarda banka seçimine ilişkin yapılan anket çalışmalarında faydalanılan kriterlerin tespit edilmesine öncülük etmişlerdir. Bu bağlamda, tespit edilen kıstaslar aynı derecede öneme sahip bulunmadığından kıstasların ağırlıklandırılmasına gerek görülmüştür. Bu çerçevede, ENTROPİ tekniği ile banka tercihine ilişkin kriterler ağırlıklandırılmıştır. Analiz kapsamında kullanılan kriterler belirlenirken, literatürde yapılan Karamustafa ve Yıldırım (2007), Taşkın vd. (2010), Adamu ve Adeola (2012), Cebeci ve Çabuk (2016) çalışmaları incelenerek belirlenmiş, bu kriterlerden faydalanılarak Tablo 1 meydana gelmiştir.

Tablo 1. Karar Kıstasları

\begin{tabular}{|c|c|}
\hline & Ana Kistaslar \\
\hline$\left(\mathrm{K}_{1}\right)$ & "Şube ve Alternatif Kanal Ağı" \\
\hline$\left(\mathrm{K}_{2}\right)$ & “Personel Özellikleri” \\
\hline$\left(\mathrm{K}_{3}\right)$ & “İşlem Kolaylığı ve Maliyet” \\
\hline$\left(\mathrm{K}_{4}\right)$ & "Bankanın Fiziki ve Teknik Yapısı" \\
\hline$\left(\mathrm{K}_{5}\right)$ & "Ürün ve Hizmet Çeşitliliği" \\
\hline$\left(\mathrm{K}_{6}\right)$ & “Bankanın Güvenilirliği” \\
\hline$\left(\mathrm{K}_{7}\right)$ & "Hız" \\
\hline
\end{tabular}




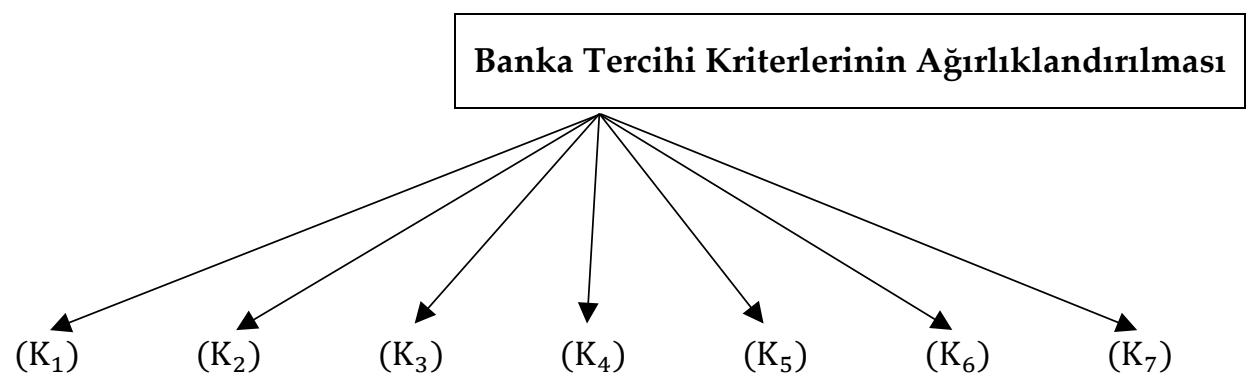

Şekil 2. Hiyerarşik Yapı

\subsection{Kriterlerin Ağırlıklandırılması}

ENTROPI yönteminden yararlanılan bu aşamada kriterlerin değerlendirilmesi için karar matrisi oluşturulmuştur. Konunun paydaşları olan akademisyenlere (3), banka uzmanlarına (10), Ticaret ve Sanayi Odası yetkililerine (2) toplamda 15 anket sunulmuştur. Çalışma verileri 06.11.2020-15.11.2020 tarihleri arasında toplanmıştır. Görüşlere ilişkin tablolar Ekler kısmında sunulmuştur. Bu doğrultuda kriterlerin ağırlıklandırılmasına yönelik olarak ENTROPİ ile ağırlıklar belirlenmiş ve Tablo 2 ‘de yer alan kriter ağırlıkları elde edilmiştir.

Tablo 2. Kriter Ağırlıkları Tablosu

\begin{tabular}{|c|c|c|c|c|c|c|c|}
\hline & $\left(\mathrm{K}_{1}\right)$ & $\left(\mathrm{K}_{2}\right)$ & $\left(\mathrm{K}_{3}\right)$ & $\left(\mathrm{K}_{4}\right)$ & $\left(\mathrm{K}_{5}\right)$ & $\left(\mathrm{K}_{6}\right)$ & $\left(\mathrm{K}_{7}\right)$ \\
\hline Ăğırlık & 0,171 & 0,170 & 0,165 & 0,167 & 0,124 & 0,043 & 0,16 \\
\hline
\end{tabular}

Tablo 2'ye göre banka işletmelerinde banka tercih kıstasları içinde en fazla öneme sahip ana kriter sırası ile "Şube ve Alternatif Kanal Ağıı", "Personel Özellikleri", "Bankanın Fiziki ve Teknik Yapısı", "İşlem Kolaylı̆̆ı ve Maliyet" ve "Hiz" olduğu tespit edilmiştir. Diğer taraftan daha az öneme sahip olan ana kriterlerin ise sırasılya "Ürün ve Hizmet Çeşitliliği" ve "Bankanın Güvenilirliği" olduğu tespit edilmiştir.

\section{SONUÇ VE TARTIŞMA}

Bu Çalışmada Giresun İli banka işletmelerindeki çalışanlara, konunun paydaşı akademisyenler ve Sanayi ve Ticaret Odası çalışanlarına anket yapılmıştır. Yapılan anketler sonucunda banka seçimini etkileyen kriterlerin önem derecelerinin boyutları tespit edilmiştir. Banka tercihi için en önemli kriter olarak "Şube ve Alternatif Kanal Ağg" olduğu tespit edilmiştir. Ayrıca bu kriteri sırasıyla "Personel Özellikleri", "Bankanın Fiziki ve Teknik Yapısı", "İşlem Kolaylığı ve Maliyet", "Hız" ve "Ürün ve Hizmet Çeşitliliğì" olduğu tespit edilmiştir. Öte yandan nispeten daha düşük derecede önemli olan ana kriterin ise "Bankanın Güvenilirliği" olduğu sonucuna ulaşılmıştır.

Bu kapsamda, "Şube ve Alternatif Kanal Ă̆g" ve "Personel Özellikleri" kriterlerinin Cebeci ve Çabuk (2016), Tepeli ve Daşkıran (2019), ve Narteh vd. (2011) çalışmaları ile birbirine benzediği belirlenmiştir. Diğer taraftan en düşük derecede öneme sahip olan öteki kıstaslarında "Bankanın Güvenilirliği i" ve "Ürün ve Hizmet Çeşitliliğĭ" faktörlerinin Mokhlis vd. (2009), Karamustafa ve Yıldırım (2007) ve Junior vd. (2013) çalışmalarıyla benzeşmediği belirlenmiştir.

Bu sonuçlara göre Giresun İli'nde tüketicilerin bir bankayı tercih etme noktasında "Şube ve Alternatif Kanla $A \breve{g} \imath$ " faktörünün ele alınması ve ATM, internet bankacılı̆̆ı, telefon bankacılığı ve mobil bankacilık gibi dijital bankacılık alanlarıyla ilgili çalışmalar yapması uygun olacaktır. Bununla birlikte önem dereceleri birbirine yakın olan "Personel Özellikleri", "Bankanın Fiziki ve Teknik Yapısı" ve "İşlem Kolaylı̆̆ı ve Maliyet" faktörlerine de önem vererek pazarlama stratejilerini geliştirmeleri gerekmektedir.

Öte yandan bankanın müşterisine vereceği hizmetin belirlenen zamanda sağlanması, müşterilerin bankaya olan bağlanma duygusunun artmasını sağlayacağından, banka personelinin müşterilerine yanlışsız, eksiksiz bir biçimde bilgiler sunması ve müşterilerin finansal gereksinimlerini vaktinde karşılayarak bankaya olan bağlanma duygularını temin etmeleri gerekmektedir. Aktarılan bu görüşlerle birlikte banka şirketlerinin yetersiz olan tarafları giderilerek, müşterilerinin taleplerinin yerine getirmesi ve bankanın tercih nedeni olmasında mühim olan fiziki ve teknik yapısının iyileştirilmesi temin edilebilir. 
A. Karavardar - A. Çilek 12/4 (2020) 3482-3492

Bundan başka sözü edilen çalışma, ilerleyen zamanlarda bulanık mantık da eklenerek gelişmesi sağlanabilir. Aynı zamanda başka çok kıstaslı karar verme teknikleri ile sezgisel bulanık TOPSís yöntemi gibi sezgisel çok kıstaslı karar verme ya da istatistiksel çalışmalardan parametrik ve parametrik olmayan başka metotlarla da analiz edilebilir. Çalışma sonuçları karşılaştırılarak savunulabilir.

\section{KAYNAKÇA}

Abdullah L. and Otheman A. (2013). A New Weight for Sub-Criteria in Interval Type- 2 Fuzzy TOPSIS and Its Application, International. Journal of Intelligent Systems and Applications, 2, 25-33.

Adamu, M. O. and Adeola, B. S. (2012). A Statistical Evaluation of Factors That Attract Customers to Banks in Lagos, Nigeria, Global Journal of Management and Business Research, 12(3), 82-88.

Akın F. (2019). Banka ve Bankacilık, Akın, F. (Ed.), Finansal Piyasalar ve Kurumlar, Ekin Yayınevi, Bursa, 71102.

Alp, İ., Öztel, A. and Köse, M.S. (2015). ENTROPİ Tabanlı MAUT Yöntemi ile Kurumsal Sürdürülebilirlik Performansı Ölçümü: Bir Vaka Çalışması, Ekonomik ve Sosyal Araştırmalar Dergisi, 11 (2), 65-82.

Anderson, W. T., Cox, E. P., and Fulcher, D. G.(1976). Bank Selection Decision and Market Segmentation, Journal of Marketing, 40 (1), 40-45.

Aregbeyen, O. (2011). The determinants of bank selection choices by customers: Recent and extensive evidence from Nigeria, International Journal of Business and Social Science, 2(22), 276-288.

Cebeci, İ. and Çabuk, Z. (2016). Tüketicilerin Banka Tercihini Etkileyen Faktörlerin Belirlenmesi: Giresun'da Bir Araştırma, Finansal Araştırmalar ve Çalışmalar Dergisi, 8(14), 57-66.

Chen, T., Jin, Y., Q1u, X. and Chen, X. (2014). A Hybrid Fuzzy Evaluation Method for Safety Assessment of Food-Waste Feed Based on Entropy and The Analytic Hierarchy Process Methods, Expert Systems with Applications, (41), 7328-7337.

Chigamba, C. and Fatoki, O. (2011). Factors influencing the choice of commercial banks by university students in South Africa, International Journal of Business and Management, 6(6), 66-76.

Çınar, Y. (2004), Çok Nitelikli Karar Verme ve Bankaların Mali Performanslarının Değerlendirilmesi Örneği, Ankara Üniversitesi Sosyal Bilimler Enstitüsü İşletme Anabilim Dall, Yüksek Lisans Tezi, Ankara.

Çiçek, H. (2013). Maksimum ENTROPI Yöntemi İle Türkiye'deki Coğrafi Bölgeleri Yıllık Hava Sıcaklık Değerlerinin İncelenmesi, Afyon Kocatepe Üniversitesi, Fen Bilimleri Enstitüsü, Yüksek Lisans Tezi, Afyonkarahisar.

Çolak, Ö. F. (2003). Piyasaya Giriş Engelleri ve Rekabet: Bankacilık Sektörü Üzerine Bir Analiz. Rekabet, Düzenlemeler ve Politikalar Kongresi, Muğla Üniversitesi, Muğla, 25-26 Eylül, 22-30.

Çöllü, D. A. and Sevim, U. (2017). Müşterilerin Banka Seçimini Etkileyen Kriterlerin Belirlenmesi: Giresun Örneği, Uluslararast İktisadi ve İdari İncelemeler Dergisi, (18), 201-220.

Devlin, J., and Gerrard, P. (2005). A study of customer choice criteria for multiple bank users, Journal of Retailing and Consumer services, 12(4), 297-306.

Erol, Cengiz and El-Bdour, Radi (1989). Attitudes, Behavior and Patronage Factors of Bank Customers Towards Islamic Banks, International Journal of Bank Marketing, 7(6), 31-37.

Hasan, S. A., Subhani, M. I. and Osman, M. (2012). Consumer criteria for the selection of an Islamic Bank: Evidence from Pakistan, International Research Journal of Finance and Economics, 94, 114-122.

Herişçakar, E. (1999). Gemi Ana Makine Seçiminde Çok Kriterli Karar Verme Yöntemleri AHP ve SMART Uygulaması, Gemi İnşaatı ve Teknolojisi Teknik Kongresi, İstanbul, 240-256.

Holstius, K. and Kaynak, E. (1995). Retail banking in Nordic countries: The case of Finland, International Journal of Bank Marketing, 13(8), 10-20.

Ibrahim, H., Abdul-Hamid, I. K. and Abdulai, M. (2020). Revisiting Young Customers' Bank Selection and Loyalty Decisions in Ghana, Athens Journal of Business and Economics, (6), 1-23. 
A. Karavardar - A. Çilek 12/4 (2020) 3482-3492

Junior, D. A., Osei, B. A. and Petershie, B. (2013). Factors affecting customer's choice of retail banking in Ghana, International Journal of Research in Social Sciences, 3(1), 37-44.

Karamustafa, K. and Yıldırım, M. (2007). Tuketicilerin Bireysel Banka Tercihine İlişkin Kayseri İlinde Yapılan Bir Araştırma, Ekonomik ve Sosyal Araştırmalar Dergisi, 3(3), 56-92.

Kaynak, E. (1986). How to Measure Your Bank' s Personality: Some Insight from Canada, International Journal of Bank Marketing, 4(2), 54-68.

Korucuk, S., Akyurt, H., and Turpcu, E. (2019). Otel işletmelerinde hizmet kalitesinin entropi yöntemi ile ölçülmesi: Giresun ilindeki üç yıldızlı oteller üzerine bir araştırma, Manas Sosyal Araştırmalar Dergisi, 8(1), 697-709.

Korucuk, S., Bozkurt, E. and Yazıcılar, F. (2018). Türk Dünyası ülkelerinin dış ticaret performans faktörlerinin ağırlıklandırılması, IV. Internatıonal Caucasus-Central Asıa Foreıgn Trade And Logistıcs Congress, September, 7-8, Didim/AYDIN, 1020-1028.

Korucuk, S., Memiş, S., and Ergün, M. (2020). Kobi'lerde İnovasyon Stratejilerinin Önceliklendirilmesine Yönelik Bir Uygulama: Giresun İli Örneği, Karadeniz Teknik Üniversitesi İletişim Araştırmaları Dergisi, 10(1), 156-168.

Laroche, M., Rosenblatt, J. A., and Manning, T. (1986). Services used and factors considered important in selecting a bank: an investigation across diverse demographic segments, International Journal of Bank Marketing, 4(1), 35-55.

Lee, P. T. W., Lin, C. W. and Shin, S. H., (2012). A Comparative Study on Financial Positions of Shipping Companies in Taiwan and Korea Using Entropy and Grey Relation Analysis, Expert Systems with Applications (39), 5649-5657.

Malekian, A. and Azarnivand, A. (2016). Application of Integrated Shannon's ENTROPY and VIKOR Techniques in Prioritization of Flood Risk in the Shemshak Watershed, Iran, Water Resources Management, 30, 409-425.

Memiş, S. (2019). Konaklama İşletmelerinde Yeşil Yönetim Uygulamalarının ENTROPI Yöntemi ile Ağırlıklandırılması: Giresun ili Örneği, İşletme Araştırmaları Dergisi, 11(1), 653-665.

Mokhlis, S., Salleh, H. S. and Mat, N. H. N. (2009). Commercial bank selection: comparison between single and multiple bank users in Malaysia, International Journal of Economics and Finance, 1(2), 263-273.

Naktiyok, A. and Küçük, O. (2003). İşgören (İç Müşteri) Ve Müşteri (Dış Müşteri) Tatmini, İşgören Tatmininin Müşteri Tatmini Üzerine Etkileri: Ampirik Bir Değerlendirme, Atatürk Üniversitesi İ.̇.B.F. Dergisi, 17(12), 225-241.

Narteh, B. and Owusu-Frimpong, N. (2011). An analysis of students' knowledge and choice criteria in retail bank selection in sub-Saharan Africa, International Journal of Bank Marketing, 29(5), 373-397.

Okpara, G. S. and Onuoha, O. A. (2013). Bank Selection and Patronage By University Students: A Survey of Students in Umudike, Nigeria, Asian Business Review, 2(2), 70-76.

Ömürbek, N., Karaatlı, M. and Balcı, H. F. (2016).Entropi Temelli MAUT ve SAW Yöntemleri ile Otomotiv Firmalarının Performans Değerlemesi, Dokuz Eylül Üniversitesi İktisadi ve İdari Bilimler Fakültesi Dergisi, 31(1), 227-255.

Özsoy, İ., Görmez, B. and Mekik, S. (2013). Türkiye'de katılım bankalarının tercih edilme sebepleri: Ampirik bir tetkik, Yönetim ve Ekonomi: Celal Bayar Üniversitesi İktisadi ve İdari Bilimler Fakültesi Dergisi, 20(1), 187-206.

Rao, S., and Sharma, D. R. (2010). Bank selection criteria employed by MBA students in Delhi: An empirical analysis, Journal of business studies Quarterly, 1(2), 56-69.

Shannon, C. E. (1948). A Note on the concept of Entropy, Bell System Tech, 27(3), 379-423.

Sohail, M. S. and Shanmugham, B. (2003). E-banking and customer preferences in Malaysia: An empirical investigation, Information sciences, 150(3-4), 207-217. 
A. Karavardar - A. Çilek 12/4 (2020) 3482-3492

Tan, Chin T., and Chua, Christina (1986). Intention, Attitude and Social Influence in Bank Selection: A Study in an Oriental Culture, International Journal of Bank Marketing, 4(3), 43-53.

Taşkın, C., Akat, O. and Erol , Z. (2010). Tuketicilerin Banka Tercihini Etkileyen Faktorlerin Belirlenmesi: Bursa' da Bir Araştırma, Anadolu Universitesi Sosyal Bilimler Dergisi, 10(3), 11-22.

Tehulu, T. A. and Wondmagegn, G. A. (2014). Factors influencing customers' bank selection decision in Ethiopia: The case of Bahir Dar City, Research Journal of Finance and Accounting, 5(21), 57-67.

Tepeli, Y. and Daşkıran, F. (2019). Finansal Tüketicilerin Banka Tercihlerinin Konjoint Model ile Belirlenmesi Üzerine Bir Araştırma: Muğla Sıtkı Koçman Üniversitesi Örneği, Mugla Sitki Kocman University Journal of Social Sciences, 20(45), 63-78.

Usta, R.(2005). Tüketicilerin İnternet Bankacıllı̆ı̆ı Kullanmama Nedenleri Üzerine Bir Araştırma, Doğuş Üniversitesi Dergisi, 6(2), 279-289.

Wu, J., Sun, J., Liang, L. and Zha, Y. (2011). Determination of Weights for Ultimate cross Efficiency Using Shannon ENTROPY, Expert Systems With Applications, 38(5), 5162-5165.

Yildiz, S., Yildiz, E. and Topal, M. H. (2014). Islamic marketing as a new marketing trend: an application for determining consumers' Islamic bank selection criteria, Banks and Bank Systems, 9(1), 22-27.

Zhang, H., Gu, C.L., Gu, L.W. and Zhang, Y. (2011). The Evaluation of Tourism Destination Competitiveness by TOPSIS \& Information ENTROPY - A case in the Yangtze River Delta of China, Tourism Management, 32, 443-451. 
A. Karavardar - A. Çilek 12/4 (2020) 3482-3492

\section{EKLER}

EK:1. Kriterler Üzerinden Elde Edilen Karar Verenlerin Karar Matrisi

\begin{tabular}{|l|c|c|c|c|c|c|c|}
\hline Kriterler & $\left(\mathrm{K}_{1}\right)$ & $\left(\mathrm{K}_{2}\right)$ & $\left(\mathrm{K}_{3}\right)$ & $\left(\mathrm{K}_{4}\right)$ & $\left(\mathrm{K}_{5}\right)$ & $\left(\mathrm{K}_{6}\right)$ & $\left(\mathrm{K}_{7}\right)$ \\
\hline$\left(\mathrm{K}_{1}\right)$ & 1,000 & 3,873 & 1,943 & 5,009 & 3,476 & 1,901 & 2,074 \\
\hline$\left(\mathrm{K}_{2}\right)$ & 2,880 & 1,000 & 2,134 & 4,187 & 3,374 & 1,952 & 2,325 \\
\hline$\left(\mathrm{K}_{3}\right)$ & 2,688 & 4,644 & 1,000 & 4,940 & 3,085 & 2,150 & 3,116 \\
\hline$\left(\mathrm{K}_{4}\right)$ & 2,560 & 2,781 & 1,698 & 1,000 & 3,465 & 1,600 & 1,844 \\
\hline$\left(\mathrm{K}_{5}\right)$ & 2,429 & 4,720 & 1,631 & 3,852 & 1,000 & 1,807 & 2,861 \\
\hline$\left(\mathrm{K}_{6}\right)$ & 2,228 & 5,019 & 4,090 & 6,482 & 4,506 & 1,000 & 4,361 \\
\hline$\left(\mathrm{K}_{7}\right)$ & 3,428 & 2,748 & 2,301 & 4,266 & 2,708 & 1,827 & 1,000 \\
\hline
\end{tabular}

EK:2. Normalize Paylaşım Tablosu

\begin{tabular}{|c|c|c|c|c|c|c|c|}
\hline Kistaslar & $\left(\mathrm{K}_{1}\right)$ & $\left(\mathrm{K}_{2}\right)$ & $\left(\mathrm{K}_{3}\right)$ & $\left(\mathrm{K}_{4}\right)$ & $\left(\mathrm{K}_{5}\right)$ & $\left(\mathrm{K}_{6}\right)$ & $\left(\mathrm{K}_{7}\right)$ \\
\hline$\left(\right.$ Kıstas $\left._{1}\right)$ & ,049 & 156 & 131 & 168 & 161 & 155 & 118 \\
\hline$\left(\right.$ Kistas $\left._{2}\right)$ & 142 & ,040 & 144 & 141 & 156 & 159 & 132 \\
\hline$\left(\operatorname{Kistas}_{3}\right)$ & 133 & 187 & ,068 & 166 & 143 & 176 & 177 \\
\hline$\left(\operatorname{Kistas}_{4}\right)$ & 127 & 112 & 115 & ,034 & 160 & 131 & 105 \\
\hline$\left(\right.$ Kistas $\left._{5}\right)$ & 120 & 190 & 110 & 130 & ,046 & 148 & 163 \\
\hline$\left(\right.$ Kistas $\left._{6}\right)$ & 259 & 202 & ,276 & 218 & 208 & ,082 & 248 \\
\hline$\left(\operatorname{Kistas}_{7}\right)$ & 170 & 111 & 156 & 143 & 125 & 149 & ,057 \\
\hline
\end{tabular}

